\title{
Efficacy of new natural biomodification agents from Anacardiaceae extracts on dentin collagen cross-linking
}

\author{
M.A. Moreira ${ }^{a}$, N.O. Souza ${ }^{b}$, R.S. Sousa ${ }^{b}$, D.Q. Freitas ${ }^{b}$, M.V. Lemos ${ }^{b}$, \\ D.M. De Paula ${ }^{b}$, F.J.N. Maia ${ }^{c}$, D. Lomonaco ${ }^{c}$, S.E. Mazzetto ${ }^{c}$, \\ V.P. Feitosa $a^{b, d, *}$ \\ a Dental School, Federal University of Ceara, Campus of Sobral, Sobral, Brazil \\ b Dental School, PPGO-UFC, Federal University of Ceara, Fortaleza, Brazil \\ c Department of Organic and Inorganic Chemistry, Federal University of Ceara, Fortaleza, Brazil \\ d Paulo Picanço School of Dentistry, Fortaleza, Brazil
}

\section{A R T I C L E I N F O}

\section{Article history:}

Received 28 March 2017

Received in revised form 7 June 2017

Accepted 8 July 2017

\section{Keywords:}

Dentin

Collagen

Biomaterials

Restorative dentistry

Biomechanics

\begin{abstract}
A B S T R A C T
Objectives. Several polyphenols from renewable sources were surveyed for dentin biomodification. However, phenols from cashew nut shell liquid (CNSL, Anacardium occidentale) and from Aroeira (Myracrodruon urundeuva) extract have never been evaluated. The present investigation aimed to compare the dentin collagen crosslinking (biomodification) effectiveness of polyphenols from Aroeira stem bark extract, proanthocyanidins (PACs) from grape-seed extract (Vitis vinifera), cardol and cardanol from CNSL after clinically relevant treatment for one minute.

Methods. Three-point bending test was used to obtain the elastic modulus of fully demineralized dentin beams before and after biomodification, whilst color change and mass variation were evaluated after four weeks water biodegradation. Color aspect was assessed by optical images after biodegradation whereas collagen cross-linking was investigated by micro-Raman spectroscopy. Statistical analysis was performed with repeated-measures two way ANOVA and Tukey's test $(\mathrm{p}<0.05)$.

Results. The increase in elastic modulus after biomodification was in the order cardol $>$ cardanol $>$ aroeira $=$ PACs with cardol solution achieving mean $338.2 \%$ increase. The mass increase after biomodification followed the same order aforementioned. Nevertheless, after four weeks aging, more hydrophobic agent (cardanol) induced the highest resistance against water biodegradation. Aroeira and cardol attained intermediate outcomes whereas PACs provided the lower resistance. Tannin-based agents (Aroeira and PACs) stained the specimens in dark brown color. No color alteration was observed with cardol and cardanol treatments. All four agents achieved crosslinking in micro-Raman after one minute application.

Significance. In conclusion, major components of CNSL yield overall best dentin biomodification outcomes when applied for one minute without staining the dentin collagen.
\end{abstract}

(c) 2017 The Academy of Dental Materials. Published by Elsevier Ltd. All rights reserved.

\footnotetext{
* Corresponding author at: Lab PPGO-UFC, Dental School, Federal University of Ceará, Rua Monsenhor Furtado S/N, Fortaleza, CE 60430-350, Brazil.

E-mail addresses: victorpfeitosa@hotmail.com, victor.feitosa@facpp.edu.br (V.P. Feitosa).

http://dx.doi.org/10.1016/j.dental.2017.07.003

0109-5641/@ 2017 The Academy of Dental Materials. Published by Elsevier Ltd. All rights reserved.
} 


\section{Introduction}

Major drawbacks in dentin bond are related to enzymatic and hydrolytic degradation of hybrid layer and resin-sparse collagen matrix [1]. It is hypothesized that the quality and longevity of the dentin adhesion may be improved by increasing the dentin collagen mechanical properties [2]. In this regard, dentin biomodification improves the stiffness of the adhesive interface and protects the collagen fibrils from biodegradation by promoting collagen crosslinking [3].

A variety of crosslinking (biomodification) agents have proved to effectively increase mechanical properties of dentin organic matrix [4]. Nevertheless, condensed tannins, also known as proanthocyanidins (PACs), from grape seed extract (Vitis vinifera) are a group of plant-derived polyphenols with highlight and high crosslink potential to collagen thereby providing biostability [3,5-7]. The positive influence of these substances on bond strength [8] and dentin properties such as ultimate tensile strength [4], resistance to demineralization/biodegradation [9,10] and elastic modulus [11,12] was described in several investigations. Due to the dark color of PACs solution, the main shortcoming for its clinical use still is the risk to stain tooth substrates [13].

Further plant extracts from Anacardiaceae such as Anacardium occidentale (cashew) and Myracrodruon urundeuva (Aroeira) [14] have potential significant capabilities for application in dentin biomodification. Cardol and cardanol are long carbon-chain phenols (Fig. 1) obtained from the industrial extraction of cashew nut shell liquid (CNSL) [15] during production of nuts. They have antioxidant capacity $[16,17]$, enzyme inhibitory potential $[18,19]$ and two hydroxyls in p-position (in the case of cardol) similar to those of PACs (Fig. 1). Extracts of Aroeira showed anti-inflammatory properties [20,21] and antimicrobial activity [22]. Moreover, major polyphenols of Aroeira are characterized by hydrolysable tannins [23] with high chemical interaction with proteins producing tannin-protein complexes relatively insoluble and resistant to degradation [24].

Although several plant-derived polyphenols were tested for dentin collagen crosslinking $[25,26]$, cardol/cardanol from cashew nut shell liquid and Aroeira extract have never been evaluated. Therefore, the aim of the present study was to determine the effects of cardol, cardanol and Aroeira extract as crosslinkers on mechanical properties and degradation of demineralized dentin in comparison to PACs within clinically relevant application time. The hypothesis tested was that cardol, cardanol, PACs and Aroeira provide similar increase on elastic modulus and mass variation of demineralized dentin beams.

\section{Materials and methods}

\subsection{Preparation of biomodification solutions}

Cardol and cardanol were obtained from industrial cashew nut shell liquid (CNSL) supplied by Amendoas do Brasil LTDA (Fortaleza, Brazil) separated employing a methodology described

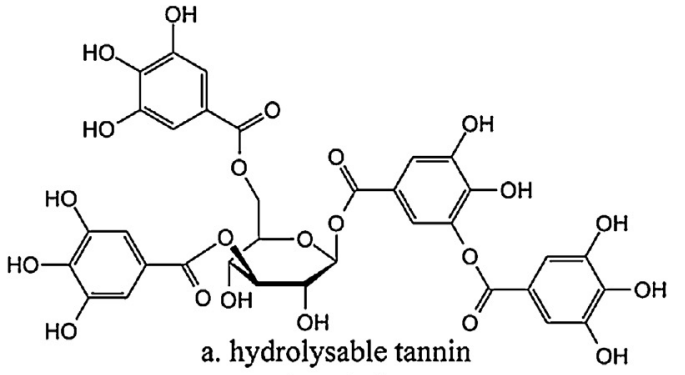

(aroeira)<smiles>CCCCCC/C=C/CCCCCCc1cccc(O)c1</smiles>

c. cardanol
$\mathrm{OH}$

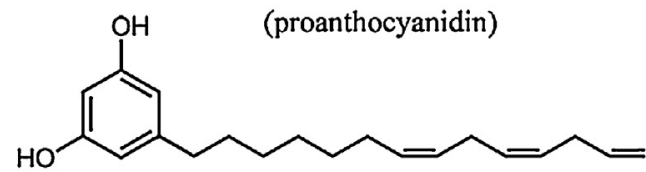

d. cardol b. condensed tannin
(proanthocyanidin)<smiles>Cc1c(O)cc(O)c2c1O[C@H](c1ccc(O)c(O)c1)[C@H](O)C2C</smiles>
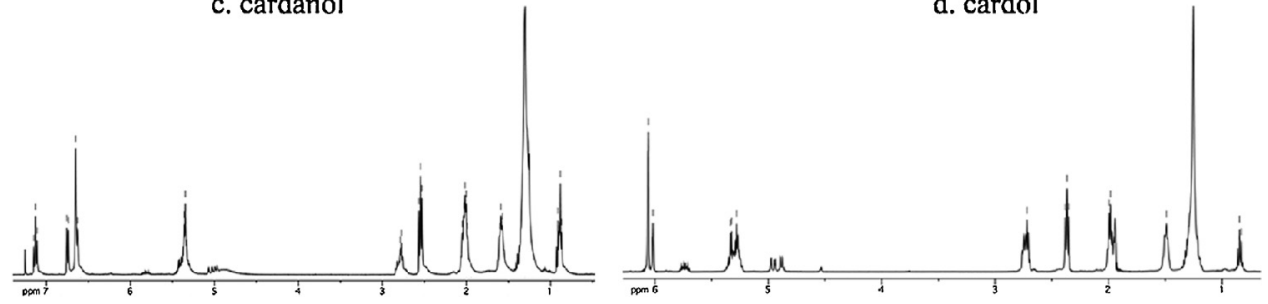

Fig. 1 - Chemical structures of biomodification agents surveyed. (a) Main polyphenol from aroeira extract. (b) Major structure of proanthocyanidins from grape seed extract. (c) Chemical structure and NMR graph of purified cardanol. (d) Chemical structure of cardol with its respective NMR graph. ${ }^{*}$ Description of nuclear magnetic resonance graphs and outcomes of gas chromatography/mass spectroscopy analyses: cardanol — Light brown oil, $\left.{ }^{1} \mathrm{H} \mathrm{NMR} \mathrm{(CDCl}{ }_{3}, \delta\right): 1,03$ (t); 1,06; 1,08; 1,36; 1,45; 1,50; 1,71; 2,19 (t, 2H); 2,65; 2,94; 2,95; 5,13 (m) 5,21 (m); 5,53 (m); 6,63 (m, 1H); 6,65 (m, 1H); 6,73 (d, 2H); 7,13 (t, 1H) ppm. GC/MS (EI): m/z = 302. Cardol — Dark brown oil, ${ }^{1} \mathrm{H}$ NMR (acetone-d6, $\left.\delta\right): 0,80$ (t); 1,26 (m); 1,51 (m); 2,05 (m); 2,39 (t); 2,75 (m); 4,94 (m); 5,32 (m); 5,77 (m); 6,02 (s, 1H); 6,06 (s, 2H) ppm. GC/MS (EI): m/z =314. 
by Lomonaco et al. [27]. The products were also characterized by gas chromatography/mass spectrometry and ${ }^{1} \mathrm{H}$ nuclear magnetic resonance (NMR) to ensure their purity [27]. The CNSL components were diluted in $\mathrm{EtOH} / \mathrm{H}_{2} \mathrm{O}$ (1:1 volume ratio) at $2 \mathrm{wt} \%$ concentration. Aroeira extract was obtained from commercial mastic stem bark (M\&A Natural Products, Fortaleza, Brazil) of $M$. urundeuva species through infusion in $\mathrm{EtOH} / \mathrm{H}_{2} \mathrm{O}$ (1:1 volume ratio) with $15 \%$ bark (15 g bark in $100 \mathrm{~mL}$ hydroethanolic solution). After $5 \mathrm{~min}$ agitation in $25^{\circ} \mathrm{C}$, the mixture was filtered twice to obtain the solution of Aroeira polyphenols with approximately $2 \%$ concentration, as the total amount of polyphenols in Aroeira stem bark is approximately 13\% [23]. Proanthocyanidins (PACs) solution was prepared after dissolving 6.5\% grape seed extract (V. vinifera, Meganatural Gold, Madera, CA, USA) in EtOH/ $\mathrm{H}_{2} \mathrm{O}$ (1:1 volume ratio) with $5 \mathrm{~min}$ agitation at $25^{\circ} \mathrm{C}$ and final double filtering. The solutions were buffered to $\mathrm{pH}$ 7.2. Ethanol/water solution was employed to standardize the dissolution of agents, once cardanol has very low solubility in only distilled water. Chemical structures of major polyphenol from Aroeira, monomeric unit of proanthocyanidins from grape-seed extract, and structures of cardol and cardanol are depicted in Fig. 1.

\subsection{Structural characterization of cardanol and cardol}

NMR spectra were recorded on Avance DRX-500 $(500 \mathrm{MHz}$ for ${ }^{1} \mathrm{H}$, Bruker, Bremen, Germany) using $\mathrm{CDCl}_{3}$ as solvent for cardanol, and acetone-d6 for cardol. The gas chromatography/mass spectrometry analyses were performed on GC/MS QP-2010 Ultra (Shimadzu, Tokyo, Japan), equipped with a (5\%-phenyl)-methylpolysiloxane (DB-5) capillary column $(30 \mathrm{~m} \times 0.25 \mathrm{~mm})$, using helium $(\mathrm{He})$ as carrier gas and a flow rate of $1 \mathrm{~mL} / \mathrm{min}$ in a splitless mode.

\subsection{Sample preparation}

Twenty five extracted caries-free human third molars were used in this study after approval by the Research Ethics Committee of Federal University of Ceará (protocol 1482602). Teeth were cut with slow-speed water-cooled diamond saw (Isomet 4000; Buehler, Lake Bluff, USA). One $0.5 \mathrm{~mm}$-thick disk from middle coronal dentin was obtained from each tooth [12]. Disks were then sectioned into dentin beams $(1.7 \mathrm{~mm} \times 0.5 \mathrm{~mm} \times 6 \mathrm{~mm})$. A total of 75 beams were obtained and were completely demineralized in $10 \% \mathrm{H}_{3} \mathrm{PO}_{4}$ solution for $5 \mathrm{~h}$ at $20^{\circ} \mathrm{C}$ [12]. Demineralization was confirmed with digital radiography.

\subsection{Dentin biomodification}

Demineralized dentin beams ( $n=15$ /group) were randomly divided in five groups and treated with distilled water (control) or one of the four biomodification solutions tested (PACs from grape seed extract, cardol, cardanol and Aroeira bark extract). Before the treatment, the initial dry weight and initial flexural modulus (three-point bending test) were assessed as previously described [12]. For biomodification, the demineralized beams were individually immersed in $1 \mathrm{~mL}$ of each solution for $1 \mathrm{~min}$, to simulate a clinically relevant time. Afterwards, beams were vigorously rinsed with distilled water for $30 \mathrm{~s}$ to remove unbound crosslinkers. The flexural modulus was reassessed immediately after immersion, and treated beams were individually stored in $1 \mathrm{~mL}$ artificial saliva containing $5 \mathrm{mM}$ HEPES, $2.5 \mathrm{mM} \mathrm{CaCl}_{2}, 0.05 \mathrm{mM} \mathrm{ZnCl}_{2}$ and $120 \mathrm{mM} \mathrm{NaCl}$ $(\mathrm{pH} 7.4)$ at $37^{\circ} \mathrm{C}$ for four weeks to undertake collagen degradation [28].

\subsection{Elastic modulus}

Specimens were tested on three-point bending set-up in a universal testing machine (Instron 4484; Instron Inc., Canton, USA), with a $5 \mathrm{~N}$ load cell at $0.5 \mathrm{~mm} / \mathrm{min}$ crosshead speed. Load-displacement curves were converted to stress-strain curves. Width and thickness of the specimens were measured and the apparent elastic modulus was calculated at 3\% strain as previously described [12]. Data were expressed in MPa, and the percentage variation in elastic modulus was calculated as the ratio of the final value (after biomodification) to the initial values (baseline).

\subsection{Mass change}

Demineralized dentin beams were weighed before $\left(\mathrm{M}_{1}\right)$ and after $\left(\mathrm{M}_{2}\right)$ dentin biomodification with an analytical balance (0.01 mg precision, AUX-220, Shimadzu, Tokyo, Japan). Further mass assessment was surveyed after 4 weeks degradation in artificial saliva $\left(\mathrm{M}_{3}\right)$. In each period, specimens were initially dried in a vacuum desiccator containing silica gel beads for $72 \mathrm{~h}$ at room temperature. Mass variation ( $\mathrm{W}_{\mathrm{mc}} \%$ ) was determined as the percentage of gain or loss in mass for each specimen as previously described [12] based on the following formula for biomodification:

$\mathrm{W}_{\mathrm{mc}}(\%)=\left[\left(\mathrm{M}_{2} \times 100\right) / \mathrm{M}_{1}\right]-100$,

where $\mathrm{M}_{1}$ is the demineralized dentin beam mass before dentin biomodification and $\mathrm{M}_{2}$ is the mass of biomodified dentin matrix. Moreover, to assess the biodegradation percentage mass variation, the following formula was used:

$\mathrm{W}_{\text {de }}(\%)=\left[\left(\mathrm{M}_{3}-\mathrm{M}_{1}\right) \times 100\right] / \mathrm{M}_{1}$,

where $M_{1}$ is the demineralized dentin beam mass before dentin biomodification and $\mathrm{M}_{3}$ is the mass of dentin matrix after four weeks artificial saliva immersion. After the final weighing, pictures of each specimen were obtained using a professional camera (Canon, Tokyo, Japan) with Macro lens (100 mm, Canon) in order to observe the final color and aspect of biomodified demineralized dentin beams.

\subsection{Micro-Raman spectroscopy}

Vibrational analysis of the demineralized dentin specimens before and after biomodification treatment as aforementioned was assessed using the Micro-Raman spectrophotometer (Xplora, Horiba JobinYvon, Paris, France) calibrated internally in zero using the silicon standard sample provided by the manufacturer. The configuration of the equipment were HeNe laser with $3.2 \mathrm{~mW}$ power, $633 \mathrm{~nm}$ laser wavelength, $10 \mathrm{~s}$ acquisition time, 5 accumulations, $1.5 \mu \mathrm{m}$ spatial resolution, $2.5 \mathrm{~cm}^{-1}$ spectral resolution, $10 \times$ magnification lens (Olympus, London, 
Table 1 - Mean (SD) of elastic modulus (MPa) of demineralized dentin specimens.

\begin{tabular}{llll} 
& Initial modulus (MPa) & Modulus after treatment (MPa) & Elastic modulus variation (\%) \\
\hline Control $\left(\mathrm{H}_{2} \mathrm{O}\right)$ & $2.76(0.8) \mathrm{a}$ & $2.62(0.6) \mathrm{a}$ & $-5.0(2.3) \mathrm{D}$ \\
Grape seed extract & $2.45(0.7) \mathrm{a}$ & $3.83(0.9) \mathrm{b}$ & $56.3(5.0) \mathrm{C}$ \\
Cardol & $2,23(0.5) \mathrm{a}$ & $9.78(2.1) \mathrm{d}$ & $338.2(45.1) \mathrm{A}$ \\
Cardanol & $2.91(1.1) \mathrm{a}$ & $6.11(1.4) \mathrm{c}$ & $109.9(16.0) \mathrm{B}$ \\
Aroeira bark extract & $2.92(0.9) \mathrm{a}$ & $4.66(1.2) \mathrm{b}$ & $59.5(7.9) \mathrm{C}$ \\
\hline
\end{tabular}

Different capital letters depict significant difference in percentage variation $(\mathrm{p}<0.05)$ whilst different tiny letters indicate statistical difference on elastic modulus $(\mathrm{p}<0.05)$.

$\mathrm{UK}$ ) and $60 \times 70 \mu \mathrm{m}$ field area. For observation of dentin collagen cross-linking, the range was $700-1800 \mathrm{~cm}^{-1}$ to survey peaks/shoulders at $1117 \mathrm{~cm}^{-1}$ and $1235 \mathrm{~cm}^{-1}$ according to a previous investigation [29]. Raman analyses were performed in triplicate per group.

\subsection{Statistical analysis}

Analysis of elastic modulus data was carried out via one-way repeated-measures ANOVA (biomodification agent), followed by Tukey's post hoc test $(p<0.05)$, after passing normality $(p=0.657)$ and equal variance $(p=0.335)$ tests. The data of percentage modulus variation results, percentage mass change after biomodification, and percentage mass variation after 4 weeks degradation were separately analyzed by one-way ANOVA and Tukey's test $(\alpha=5 \%)$.

\section{Results}

NMR analysis demonstrated $99.8 \%$ purity and detection of solely cardanol (Fig. 1c) and cardol (Fig. 1d) structures separately. Means of elastic modulus and standard deviations are presented in Table 1 . The statistical analysis depicted significant differences between biomodification groups when compared to control group $(p<0.05)$. Modulus was significantly increased by biomodification regardless the agent used. The higher results were observed when using cardol (mean $338.2 \%$ increase) followed by cardanol (mean 109.9\% increase). The treatments with Aroeira (mean 59.5\% increase) and proanthocyanidins from grape-seed extract (mean $56.3 \%$ increase) were statistically similar and achieved higher modulus than control (distilled water), but lower than CNSL reagents.

Mass change outcomes are shown in Table 2. Cardol provided the highest increase of weight after biomodification, followed by cardanol. Aroeira (mean $8.6 \%$ ) and PAC (mean $9.1 \%)$ induced similar mass increase $(p=0.739)$. After four weeks water degradation, control demonstrated mean $39.5 \%$ mass decrease which was statistically similar $(p=0.892)$ to PAC (mean 38.6\% decrease). Cardol and Aroeira presented
Table 2 - Mean (SD) of mass variation (\%) of dentin specimens.

\begin{tabular}{lll} 
Mass variation (\%) & After biomodification & $\begin{array}{l}4 \text { weeks } \\
\text { degradation }\end{array}$ \\
\hline Control (distilled water) & $+0.8(0.3) \mathrm{d}$ & $-39.5(6.9) \mathrm{C}$ \\
Grape seed extract & $+9.1(3.0) \mathrm{C}$ & $-38.6(4.3) \mathrm{C}$ \\
Cardol & $+22.9(5.8) \mathrm{a}$ & $-21.5(2.9) \mathrm{B}$ \\
Cardanol & $+15.1(2.2) \mathrm{b}$ & $-5.0(2.3) \mathrm{A}$ \\
Aroeira bark extract & $+8.6(1.8) \mathrm{C}$ & $-19.8(7.6) \mathrm{B}$ \\
\hline
\end{tabular}

Different letters indicate statistically significant difference $(\mathrm{p}<0.05)$ within each column

lower mass reduction (mean $21.5 \%$ and $19.8 \%$ respectively) in comparison to control and PAC ( $\mathrm{p}<0.05)$. Cardanol afforded the highest resistance against biodegradation with mean $5 \%$ mass decrease.

Representative pictures of specimens after biodegradation are presented in Fig. 2. Dark color was observed in specimens treated with PAC and Aroeira whilst those treated with cardol and cardanol did not demonstrate signs of pigmentation. Control specimens depicted aspect of highly degraded demineralized dentin. Raman spectra (Fig. 3) showed, for all four biomodification agents, emergence of a shoulder at approximately $1117 \mathrm{~cm}^{-1}$ and increase of a peak at $1235 \mathrm{~cm}^{-1}$ which represents collagen crosslinking.

\section{Discussion}

The present study determined the effectiveness of three new plant-derived compounds as biomodifiers in fully demineralized dentin. It was observed differences in specimens' elastic moduli among experimental solutions, and biodegradation rates were strikingly distinct. Therefore, the tested hypothesis needs to be rejected.

Crosslinking of dentin may afford stabilization, biodegradation resistance and strengthening to collagen matrix [26]. More stable and resistant collagen network is highly significant for its function as a scaffold substrate for dental adhesive infiltration [30]. The use of biomodification agents is pro-

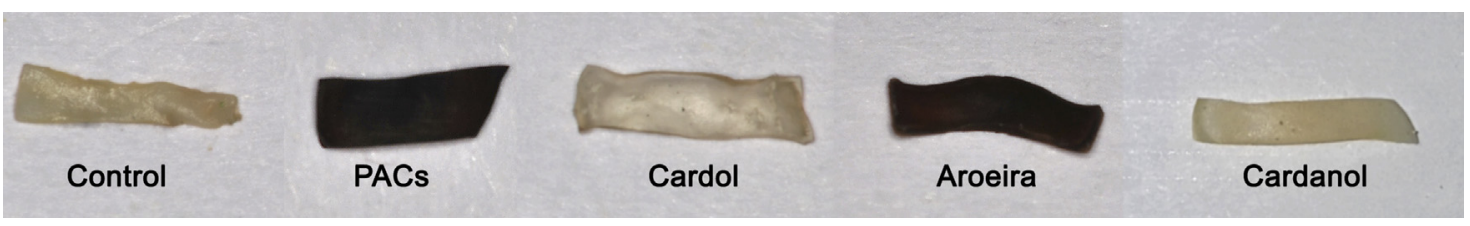

Fig. 2 - Color aspect of demineralized dentin specimens after four weeks biodegradation in artificial saliva. (For interpretation of the references to color in the text, the reader is referred to the web version of this article.) 

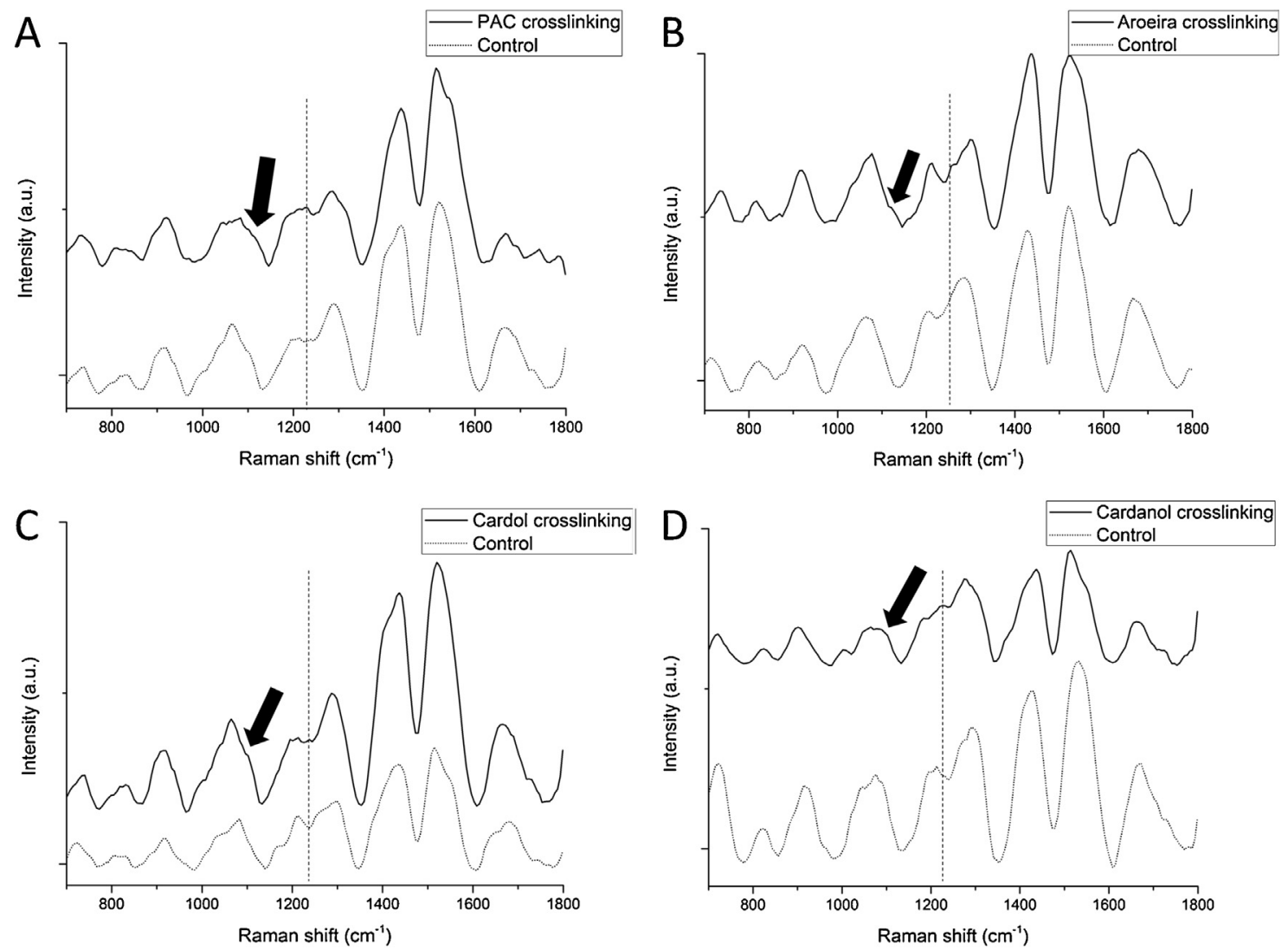

Fig. 3 - Vibrational spectra of micro-Raman analysis from same specimens before and after 1 min biomodification treatment. All reagents induced emergence of shoulder at $\sim 1117 \mathrm{~cm}^{-1}$ (black arrow) and increase of Amide III peak at $1235 \mathrm{~cm}^{-1}$ (dotted line) which demonstrates collagen crosslinking according to Liu et al. [29]. (A) Spectra of treated (black) and untreated (grey) specimens subjected to treatment with proanthocyanidins of grape seed extract. (B) Spectra of treated (black) and untreated (grey) specimens submitted to treatment with Aroeira extract. (C) Spectra of treated (black) and untreated (grey) specimens which undergone treatment with $2 \mathrm{wt} \%$ cardol solution. (D) Spectra of treated (black) and untreated (grey) specimens subjected to treatment with $2 \mathrm{wt} \%$ cardanol solution.

posed to improve mechanical properties of the dentin, to increase resin-dentin bond strength, to reduce biodegradation rates of demineralized collagen and, consequently, to extend the longevity of adhesive restorations [2,4,31]. However, one limitation of the present investigation and research design comprises the usage of $0.5 \mathrm{~mm}$-thick demineralized dentin specimens, whilst the phosphoric acid demineralized thickness of dentin in the clinical scenario represents only few micrometers [10]. Indeed, the cross-linking potential of tested biomodification agents might be improved in a thinner zone for interaction.

Tannins are natural and biocompatible polyphenols [14] with outstanding potential as biomodification agents [26] due to their high molecular weight and tendency to form complex aggregates with proteins. In this study, two main categories of tannins were tested: the hydrolysable tannins, which are present in Aroeira bark extracts (M. urundeuva) [23] and condensed tannins or proanthocyanidins (PACs), the principal polyphenols of grape-seed extract [26]. Furthermore, we tested cardol and cardanol from CNSL. To our knowledge, this is the first study to survey cardanol and cardol for dentin interaction (and dental research).
Biomodification agents with lower molecular weight (such as cardol and cardanol) may attain greater and faster penetration in dentin collagen matrix [32], which may explain the highest increase in mass and in elastic modulus after 1 min application of cardol and cardanol solutions (Tables 2 and 1 respectively). Crosslinking of dentin collagen may occur mainly via hydrogen bonding (with natural agents) and covalent bonds (with synthetic agents) [26] as demonstrated by micro-Raman spectroscopy (Fig. 3). The chemical structures of cardol and cardanol are similar, except for the number of phenolic hydroxyls, as cardanol has one hydroxyl (Fig. 1c) whilst cardol possesses two (Fig. 1d). Indeed, the role of one hydroxyl in promoting dentin biomodification may be demonstrated when comparing cardol and cardanol; thus, the higher capacity of cardol to induce hydrogen bonding crosslinks may explain the foremost increase in flexural modulus of demineralized dentin in comparison with cardanol (Table 1). Moreover, cardol and cardanol have a long 15-carbon alkyl side chain (Fig. 1), thereby providing additional hydrophobic interaction [26] with dentin collagen fibrils which may contribute to biomodification. On the other hand, tannins of Aroeira 
and grape-seed extract are unlikely to induce formation of hydrophobic interactions.

Apart from the increase in elastic modulus, the biodegradation resistance is related not only to the formation of collagen crosslinks, but also with the hydrophilicity of the biomodification agent [7]. Cardol and cardanol are relatively hydrophobic in comparison with tannins, but the former is slightly more hydrophilic than the latter due to the additional hydroxyl. More hydrophobic feature of cardanol jeopardizes the dentin diffusion and increase of mass after treatment. However, collagen fibrils connected with cardanol molecules might tend to become more hydrophobic, avoiding the water seepage during 4-week storage and consequently diminishing collagen degradation (Table 2).

Although PACs present multiple free phenol functionalities (Fig. 1b), the oligomeric structures which have high biomodification potency [33], also have higher molecular weight, what could justify their slower diffusion in collagen matrix, thereby explaining the reduced effectiveness in increasing elastic modulus and degradation resistance when applied for $1 \mathrm{~min}$. Most investigations depicted the efficacy of PACs from grape-seed extract when they were applied for $1 \mathrm{~h}$ or longer periods $[4,11,12]$. However, the efficacy of PACs in clinically relevant application time has also been demonstrated in thin (few micrometers) demineralized dentin layer [10].

Hydrolysable tannins were related to some interactions with proteins [23]. However, none of the biomodification studies have tested their effects on the dentin collagen matrix [26]. Aroeira bark extract has representative hydrolysable tannins with many galloyl groups (Fig. 1a) which are able to interact through hydrogen bonds with the side chains of hydroxyl, carboxyl-amine or amide groups of the collagen molecules [5] and capable of inducing more covalent and non-covalent bonds $[3,26]$. The formation of these hydrogen bonds may occur lately after partial hydrolysis of the polyphenols during water storage. Therefore, although the positive effect on elastic modulus was similar (Table 1) between both tannins (PACs and Aroeira), the degradation resistance after using hydrolysable tannins (Aroeira bark extract) solution was augmented in comparison with PACs (Table 2), likely due to later formation of collagen crosslinks.

One of the benefits of using biomodification agents to crosslink dentinal collagen is that during formation of crosslinker-protein bonds, they may remove proteoglycans from dentin matrix, replace water bound to fibrillar collagen and reduce hydrophilicity [7] what may also afford higher diffusion of resin monomers into the fully expanded collagen network [32]. Hence, they are able to reduce biodegradation rates $[26,31]$. Indeed, such mechanism of improving adhesive penetration and increasing longevity of adhesive interfaces needs to be verified for these new biomodification agents surveyed in this study.

Dentin specimens treated with PACs and Aroeira presented brownish color (Fig. 2). This color change outcome may be attributed to their oxidative properties, dark color of solutions and content of polymeric high-molecular weight polyphenols $[13,14,26]$. Although pure cardol and cardanol are dark oils, their solutions are transparent and treated specimens did not depict noteworthy color alteration (Fig. 2). This may be explained by their lower molecular weight and lesser capacity to form polymeric structures. In fact, the color stability of dentin after biomodification with cardanol and cardol might be considered another advantage for their clinical use and a drawback when using PACs and Aroeira solutions.

Cardol and cardanol correspond to more than $95 \%$ of the composition of technical cashew nut shell liquid produced in the industries [27]. Such liquid is a product of discard (byproduct) resulted from the boiling of nuts and it was estimated that one million tons are produced yearly worldwide [34]. This liquid cannot be released in the environment [27] due to its very slow natural biodegradation. Therefore, dental application of cardol and cardanol may represent a sort of "recycling" process thereby providing useful utilization in restorative dentistry with sustainability.

Cardol and cardanol are non-cytotoxic [15] compounds in low concentrations possessing antioxidant effects [16] and, similar to PACs [13], they present inhibition of matrix metalloproteinase-2 and matrix metalloproteinase-9 [18]. Both cardol and cardanol demonstrated remarkable potential as dentin biomodification agents in the present investigation as also demonstrated by micro-Raman spectroscopy (Fig. 3), attaining the highest increase in stiffness of demineralized dentin and resistance to degradation without specimens' staining.

Furthermore, unlike polyphenols from Aroeira and PACs, both reagents are single molecules (Fig. 1) prone to chemical synthesis of dental monomers which would afford the designing of collagen-binding and collagen-crosslinking monomers with substantial perspective for dentin bond. Indeed, further studies are needed to understand long-term benefits of these Anacardiaceae derived crosslinkers as well as their biocompatibility with odontoblast-like cells. In conclusion, cardol demonstrated the highest potential to increase the elastic modulus of demineralized dentin whilst cardanol treatment attained the lowest degradation. Both reagents from cashew nut shell liquid achieved overall best outcomes without staining dentin specimens.

\section{Acknowledgment}

This research was supported by CNPq-Brazil (grant 457931/2014-0). The authors have no financial interest in any of the products used in this study.

\section{REFEREN CES}

[1] Hashimoto M. A review-micromorphological evidence of degradation in resin-dentin bonds and potential preventional solutions. J Biomed Mater Res B Appl Biomater 2010;92(1):268-80

[2] Fang M, Liu R, Xiao Y, Li F, Wang D, Hou R, et al. Biomodification to dentin by a natural crosslinker improved the resin-dentin bonds. J Dent 2012;40(6):458-66.

[3] Vidal CMP, Aguiar TR, Phansalkar R, McAlpine JB, Napolitano JG, Chen SN, et al. Galloyl moieties enhance the dentin biomodification potential of plant-derived catechins. Acta Biomater 2014;10(7):3288-94.

[4] Bedran-Russo AK, Castellan CS, Shinohara MS, Hassan L, Antunes A. Characterization of biomodified dentin matrices 
for potential preventive and reparative therapies. Acta Biomater 2011;7(4):1735-41.

[5] Han B, Jaurequi J, Tang BW, Nimni ME. Proanthocyanidin: a natural crosslinking reagent for stabilizing collagen matrices. J Biomed Mater Res A 2003;65(1):118-24.

[6] Bedran-Russo AK, Vidal CM, Dos Santos PH, Castellan CS Long-term effect of carbodiimide on dentin matrix and resin-dentin bonds. J Biomed Mater Res B Appl Biomater 2010;94(1):250-5.

[7] Leme AA, Vidal CMP, Hassan LS, Bedran-Russo AK. Potential role of surface wettability on the long-term stability of dentin bonds after surface biomodification. J Biomech 2015;48(10):2067-71.

[8] Al-Ammar A, Drummond JL, Bedran-Russo AK. The use of collagen crosslinking agents to enhance dentin bond strength. J Biomed Mater Res B Appl Biomater 2009;91(1):419-24.

[9] Pavan S, Xie Q Hara AT, Bedran-Russo AK. Biomimetic approach for root caries prevention using a proanthocyanidin-rich agent. Caries Res 2011;45(5):443-7.

[10] Liu Y, Chen M, Yao X, Xu C, Zhang Y, Wang Y. Enhancement in dentin collagen's biological stability after proanthocyanidins treatment in clinically relevant time periods. Dent Mater 2013;29(4):485-92.

[11] Castellan CS, Pereira PNR, Grande RHM, Bedran-Russo AK. Mechanical caracterization of proanthocyanidin-dentin matrix interaction. Dent Mater 2010;26(10):968-73.

[12] Aguiar TR, Vidal CMP, Phansalkar RS, Todorova I, Napolitano JG, McAlpine JB, et al. Dentin biomodification potential depends on polyphenol source. J Dent Res 2014;93(4):417-22.

[13] Scheffel DLS, Hebling J, Scheffel RH, Agee K, Turco G, Souza-Costa CA, et al. Inactivation of matrix-bound matrix metalloproteinases by crosslinking agents in acid-etched dentin. Oper Dent 2014;39(2):152-8.

[14] Machado AC, Dezan Junior E, Gomes-Filho JE, Cintra LTA, Ruviére DB, Zoccal R, et al. Evaluation of tissue reaction to Aroeira (Myracrodruon urundeuva) extracts: a histologic and edemogenic study. J Appl Oral Sci 2012;20(4):414-8.

[15] Chandregowda V, Kush A, Reddy GC. Synthesis of benzamide derivatives of anacardic acid and their cytotoxic activity. Eur J Med Chem 2009;44(6):2711-9.

[16] Trevisan MTS, Pfundstein B, Haubner R, Würtele G, Spiegelhalder B, Bartsch H, et al. Characterization of alkyl phenols in cashew (Anacardium occidentale) products and assay of their antioxidant capacity. Food Chem Toxicol 2006;44(2):188-97.

[17] Kubo I, Masuoka N, Ha TJ, Tsujimoto K. Antioxidant activity of anacardic acids. Food Chem 2006;99(3):555-62.

[18] Omanakuttan A, Nambiar J, Harris RM, Bose C, Pandurangan $\mathrm{N}$, Varghese RK, et al. Anacardic acid inhibits the catalytic activity of matrix metalloproteinase-2 and matrix metalloproteinase-9. Mol Pharmacol 2012;82(4):614-22.

[19] Masuoka N, Nihei K, Maeta A, Yamagiwa Y, Kubo I. Inhibitory effects of cardols and related compounds on superoxide anion generation by xanthine oxidase. Food Chem 2015;166:270-4.

[20] Souza SMC, Aquino LCM, Milach Jr AC, Bandeira MA, Nobre ME, Viana GSB. Antiinflamatory an antiulcer properties of tannins from Myracrodruon urundeva Allemão

(Anacardiaceae) in rodents. Phytother Res 2007;21(3):220-5.

[21] Viana GS, Bandeira MA, Matos FJA. Analgesic and antiinflamatory effects of chalcones isolated from Myracrodruon urundeva Allemão. Phytomedicine 2003;10(2-3):189-95.

[22] Farias DF, Souza TM, Viana MP, Soares BM, Cunha AP, Vasconcelos IM, et al. Antibacterial, antioxidant and anticholinesterase activities of plant seed extracts from Brazilian semiarid region. Biomed Res Int 2013;2013, article ID 510736.

[23] Calou I, Bandeira MA, Aguiar-Galvão W, Cerqueira G, Siqueira R, Neves KR, et al. Neuroprotective properties of a standardized extract from Myracrodruon urundeuva Fr. All. (Aroeira do Sertao), as evaluated by a Parkinsonís disease model in rats. Parkinsons Dis 2013;2014, article ID 519615.

[24] Schofield P, Mbugua DM, Pell AN. Analysis of condensed tannins: a review. Anim Feed Sci Technol 2001;91(1-2):21-40

[25] Castellan CS, Bedran-Russo AK, Karol S, Pereira PN. Long-term stability of dentin matrix following treatment with various natural collagen cross-linkers. J Mech Behav Biomed Mater 2011;4(7):1343-50.

[26] Bedran-Russo AK, Pauli GF, Chen SN, McAlpine J, Castellan CS, Phansalkar RS, et al. Dentin biomodification: strategies, renewable resources and clinical applications. Dent Mater 2014;30(1):62-76.

[27] Lomonaco D, Maia FJN, Mazzetto SE. Thermal evaluation of cashew nutshell liquid as new bioadditives for poly(methyl methacrylate). J Therm Anal Calorim 2013;111:619-26.

[28] Tezvergil-Mutluay A, Seseogullari-Dirihan R, Feitosa VP, Tay FR, Watson TF, Pashley DH, et al. Zoledronate and ion-releasing resins impair dentin collagen degradation. J Dent Res 2014;93(10):999-1004.

[29] Liu Y, Bai X, Li S, Liu Y, Keightley A, Wang Y. Molecular weight and galloylation affect grape seed extract constituents' ability to cross-link dentin collagen in clinically relevant time. Dent Mater 2015;31(7):814-21.

[30] Bedran-Russo AK, Yoo KJ, Ema KC, Pashley DH. Mechanica] properties of tannic-acid treated dentin matrix. J Dent Res 2009;88(9):807-11.

[31] Tjäderhane L, Nascimento FD, Breschi L, Mazzoni A, Tersariol ILS, Geraldeli S, et al. Optimizing dentin bond durability: control of collagen degradation by matrix metalloproteinases and cysteine cathepsins. Dent Mater 2013;29(1):116-35.

[32] Epasinghe DJ, Yiu CKY, Burrow MF, Tsoi JKH, Tay FR. Effect of flavonoids on the mechanical properties of demineralized dentine. J Dent 2014;42(9):1178-84.

[33] Nam JW, Phansalkar RS, Lankin DC, Bisson J, McAlpine JB, Leme AA, et al. Subtle chemical shifts explain the NMR fingerprints of oligomeric proanthocyanidins with high dentin biomodification potency. J Org Chem 2015;80(15):7495-507.

[34] Kotzebue LRV, Ribeiro FWM, Sombra VG, Feitosa JPA, Mele J, Mazzetto SE, et al. Spectral and thermal studies on the synthesis and catalyzed oligomerization of novel cardanol-based benzoxazines. Polymer 2016;92:189-200. 